UDC $316.77+316.334 .56$

LBC 60.524

\title{
GAMING SPACES AND THE CHANGING EXPERIENCE OF URBAN COMMUNICATIONS
}

\author{
Olga V. Sergeyeva \\ Sociological Institute of the RAS - Branch of the Federal Center of Teoretical and Applied Sociology \\ of the Russian Academy of Sciences, Saint Petersburg, Russian Federation \\ Nadezhda A. Zinovyeva \\ Sociological Institute of the RAS - Branch of the Federal Center of Teoretical and Applied Sociology \\ of the Russian Academy of Sciences, Saint Petersburg, Russian Federation
}

\begin{abstract}
Thanks to mobile technologies, a modern city exists as an intersection of real and virtual worlds, combining face-to-face and online communications. Also, a city is a constantly recreated object in virtual gaming spaces and is not just a passive background, but an important resource for the development of gameplay. Hybridization as the addition of physical space to virtual space, and transmediation as the free transfer of content between different platforms, provide new opportunities for citizens to participate and observe urban life. The article's aim is a conceptualization of changes in the urban communication experience on the example of commemorative activities. The authors discuss the case of the Victory Parade on May 9, 2020, which was hosted by gamers in the online space, but thanks to streamers it was broadcast to a wide audience. All participants tried to somehow correspond to a real parade: they used equipment and combat subunits (units), chose locations similar to urban squares, tried to walk, ride or fly in formation, used the marches or songs of the war years. Both gamers and official teams of game developers created their parades. Authors concluded that gaming space, its architecture, and artifacts are of essential importance for this event and creates the basis for a full, partial, or creative reconstruction of the event. The authors note that online games are changing the experience of urban interactions, becoming a platform for both communication and maintaining cultural patterns, for example, for developing citizen rituals. The reproduction of urban rituals in gaming spaces reconfigures the collaborative social activities of nowadays citizens.

Key words: urban sociology, computer games, streams, playful spaces, urban spaces, hybrid reality, transmedia, commemorative activities.
\end{abstract}

УДК $316.77+316.334 .56$

ББК 60.524

\section{ИГРОВЫЕ КОМПЬЮТЕРНЫЕ СРЕДЫ И МЕНЯЮЩИЙСЯ ОПЫТ ГОРОДСКИХ КОММУНИКАЦИЙ}

\author{
Ольга Вячеславовна Сергеева \\ Социологический институт РАН - филиал ФНИСЦ РАН, г. Санкт-Петербург, Российская Федерация \\ Надежда Андреевна Зиновьева \\ Социологический институт РАН - филиал ФНИСЦ РАН, г. Санкт-Петербург, Российская Федерация
}

Аннотация. Благодаря мобильным технологиям современный город существует как пересечение ре-
ального и виртуального миров, сочетает коммуникации лицом к лицу и онлайн опыт. Кроме того, сам город
является постоянно воссоздаваемым объектом в виртуальной игровой среде, и выступает не просто фоном,
но важным ресурсом развития игровых взаимодействий. Гибридизация, проявляющаяся в дополнении фи-
зического пространства виртуальными объектами, и трансмедиация, отражающая процесс свободной пере-
дачи контента между разными платформами, дают новые возможности горожанам для участия и наблюде-
ния жизни города. Цель статьи - теоретическое и эмпирическое обоснование изменений в опыте городских 
коммуникаций. Анализируемым кейсом стали праздничные (мемориальные) мероприятия, проведенные в период пандемии. Авторы обсуждают случай с парадом Победы 9 мая 2020 года, который был организован игроками в онлайн-пространстве, но благодаря стримерам транслировался для широкой аудитории. Все участники так или иначе стремились в чем-то соответствовать настоящему парадному шествию: задействовали технику и боевые подразделения (юниты), выбирали локации, похожие на пространство площадей, старались идти, ехать или лететь в строю, использовали музыку маршей или песен военных лет. Свои парады создавали и игроки, и официальные команды разработчиков игр. Авторы делают вывод, что игровое пространство, его архитектура и комплекс артефактов, имеют первостепенное значение для проведения данного мероприятия и создают базу для полной (парад обычно проводится в этой городской среде), частичной (есть вымышленные элементы) или творческой реконструкций (парад проводится в пространстве, где он пройти не может) события. Авторы отмечают, что виртуальные игры меняют опыт городских коммуникаций, становятся площадкой как для общения, так и для поддержания культурных образцов, например, для проведения городских ритуалов. Воспроизводство городских ритуалов, культурное погружение в ритуализированные практики в игровых урбанизированных средах реконфигурирует совместную социальную деятельность современных горожан.

Ключевые слова: социология города, компьютерные игры, стримы, игровые пространства, гибридная реальность, ритуалы меморации.

\section{Введение}

Почти три десятилетия назад разработчик У. Райт произвел настоящий фурор своей игрой «SimCity» (1989)1, которая стала основополагающей работой для жанра градостроительных симуляторов. Игра была очень перспективной для своего времени, предоставляя сценарии строительства и управления городом для «виртуальных мэров» в таких условиях, как: охваченный преступностью Детройт, землетрясение в Сан-Франциско, авария атомной электростанции в Бостоне или прибрежное наводнение из-за глобального потепления в Риоде-Жанейро. Программное обеспечение для моделирования «SimCity» заложило основную логику игрового компьютерного города - возможность имитировать как городское планирование, так и социальную - экономическую и политическую - динамику в рамках некоторых гипотетических сценариев с использованием мультиагентных систем. Игра SimCity вызвала дискуссии и в любительских, и в академических кругах относительно значения таких симуляторов для развития опыта городских коммуникаций.

Сегодня мы можем сказать, что знания о пространственном дизайне и обустройстве мест, которые были восприняты игровой индустрией за короткий промежуток времени, поразительны. Всего за несколько десятилетий разработчики игр смогли освоить и приспособить многие характеристики того, что делает физическое место интересным и за- поминающимся для человека. В играх воспроизводятся пространства, удивительно точно повторяющие реальные города нашей планеты, которые в иммерсивной среде становятся «чувственно убедительными» [Álvarez, Duarte 2018].

Публикации, в которых поднимаются вопросы развития онлайн-игр, города, архитектуры и социальной активности, образуют, по нашему мнению, два тематических потока:

- nервый охватывает издания с акцентом на пространствах в играх и моделируемой виртуальной среде обитания [Горбушина, Чеботарев 2020; Ильин 2020; Салин, Галанина 2016; Álvarez, Duarte 2018; Koutsabasis 2012; Minnery, Searle 2014; Walz 2010 и др.];

- второй представлен текстами, дающими представление об экспансии игр (первазивных, иммерсивных) в жизнь реальных городов [Вахштайн web; Глазков 2015; Королева и др. 2017; МакГонигл 2015; Саблина 2018; Leorke 2018; Sicart 2016 и др.].

Есть также интегративные работы, задающие тон в изучении взаимосвязей городских и игровых пространств. Среди российских авторов следует признать вклад А. С. Ветушинского [Ветушинский 2017], сделавшего основательную статью-рецензию, которая вводит в контекст исследований видеоигровых пространств в целом. Разбираемые им идеи в развернутом виде изложены в англоязычных публикациях [Nitsche 2008; Borries, Walz, Böttger (ed.) 2007]. Кроме того, важный теоретический фундамент дают исследования современ- 
ного медийного города как гибридного пространства, в котором жизнь людей воспроизводится сразу в нескольких «слоях» онлайн и оффлайн взаимодействий [Маккуайр 2014; De Souza, Frith 2012; DeSouza, Hjorth 2009].

Таким образом, компьютерные игры дают современному человеку управляемую и наблюдаемую среду, в которой поведение многих участников и их действия влияют на результирующие обустройство и планировку местности. В играх есть изменяемая территориальная организация, распределение контроля, задачи для многопользовательских действий и преобразований в процессе игры, в которых не только первоначальный создатель определяет общий результат дизайна, но и сами игроки. По мнению П. Куцабасиса, специалиста в области НCI и дизайна, растущий интерес сообщества архитекторов к виртуальным мирам обусловлен схожими качествами их действий (уже привычные подобны открытым цифровизацией): «общение, воплощение, совместная деятельность, трехмерная визуализация, а также ориентация на последующий пользовательский опыт» [Koutsabasis 2012, 358]. Разработка игр дает понять, что пространственный дизайн и локализация - это не просто вопрос создания реалистичной среды. Пространство зависит не только от формы, но и от того, как формальные качества среды вызывают реакцию людей, варьирующуюся в гаммах поведения и привязанностей. Благодаря складывающимся сегодня альянсам города и обживаемых игровых пространств кодируются городские модели и урбанистические режимы, которые осваиваются и интерпретируются в процессе игры.

Меняющиеся под влиянием компьютерных игр пространственные практики представляют собой актуальный предмет для научного анализа в силу того, что они воплощают действия, поддерживаемые быстро совершенствующейся технологией (в частности, искусственного интеллекта), и разворачиваются на пересечении реального и виртуального. Представляется логичным, что социологический подход с его вниманием к воспроизводству порядка с помощью разных символических инструментов, вносит вклад в понимание тенденций трансмедиации (свободного «путешествия» контента с одной платформы на дру- гую) и гибридизации (постоянного дополнения онлайн и офлайн впечатлений горожанина). Трансмедиация и гибридизация проявляются в том, как проектирование пространства индустрией интерактивных развлечений становится востребованным не только для поддержания процесса игры, но включается в разнообразные институциональные взаимодействия и коммуникации (образование, урбанистика, медицинский уход и реабилитация и т. д.). В данной статье мы рассмотрели соединение игрового пространственного дизайна и практик меморации, проходящих обычно в городе. Наша цель - обосновать теоретически и эмпирически изменение опыта городских коммуникаций под влиянием возможностей игровой компьютерной среды.

\section{Поворот к гибридному опыту городских коммуникаций}

Гаджеты второго десятилетия XXI в. мобильны. Пользователи могут не только подключаться к Интернету в любом месте и в любое время, они также могут использовать устройства для сопоставления своих точных географических координат и доступа к информации об окружающей городской территории, могут получать данные о местонахождении других людей поблизости. Распространение мобильных технологий, связывающихся с физическим окружением пользователя, требует нового понимания того, как мы определяем общественные пространства. В книге «Мобильные интерфейсы в общественных местах: конфиденциальность, контроль и общение в городах» А.С. Соуза и Дж. Фрит исследуют эти социальные и пространственные изменения, рассматривая развитие технологии геолокации в контексте других мобильных и портативных технологий. Наши мобильные устройства обеспечивают интерфейсы не только для входа в виртуальный мир, но и для интенсивной связи с окружающим физическим пространством, то есть служат нам как системы, одновременно и фильтрующие информацию, и меняющие возможности коммуникации и среды, в которой происходит социальное взаимодействие [De Souza, Frith 2012].

Гибридные пространства возникают, когда виртуальные сообщества (чаты, группы в 
социальных сетях, многопользовательские онлайн-игры, стримы и т. п.), ранее действовавшие в зоне, понимаемой как киберпространство, мигрировали в физические пространства из-за распространения мобильных технологий с их всепроникающими интерфейсами. Мобильные интерфейсы смартфонов и носимой электроники, позволяют пользователям постоянно подключаться к Интернету во время перемещения по городу. Следовательно, гибридные пространства определяются эффектами действия мобильных технологий в городе: переход от статичных интерфейсов к мобильным поддерживает сети онлайн-отношений в момент городских коммуникаций пользователя, при этом стираются традиционные границы между физическим и цифровым пространствами, а городской опыт реконфигурируется. В гибридных пространствах впечатления и коммуникации горожанина поддерживаются откликами физической городской и цифровой виртуальной сред одновременно.

Игровая индустрия еще в начале 2000-х отреагировала на открывшиеся возможности гибридного опыта городских коммуникаций. В 2004-м г. в Японии была выпущена мобильная игра «Mogi», связывающая сообщество игроков с городом на основе геолокации. Ее игровая цель - искать виртуальных существ, разбросанных по Токио. В игре еще не было возможностей дополненной реальности как в последствии в PokemonGo, оснащенные сотовыми телефонами с поддержкой Јava, пользователи могли видеть на своих мобильных экранах карту города и расположение близлежащих объектов. Когда пользователи оказывались в пределах 300 метров от своих целей, объекты можно было «ловить» и загружать в сотовые телефоны [Licoppe 2017].

В текущем десятилетии игры формата «дополненной реальности» («Pokemon Go» 2016, «Ingress» 2013) были освоены горожанами по всему миру, дав повод для обсуждений нового мира, видимого в привычных пейзажах через экран смартфона, подталкивая социологов к дискуссии о модусах присутствия в совместной деятельности [Глазков 2017]. Все чаще игра с пространством переносится и в домашние пределы: например, игрушки «Johnny the Skull» или детские pacкраски с AR генерируют виртуальные симу- ляции, раздвигая видимую материальную среду дома.

Итак, город как пространство состоит из взаимодействий и материальной инфраструктуры, делающей эти взаимодействия возможными. В сегодняшних гибридных городских пространствах взаимодействия опосредованы мобильными технологиями, и горожане могут постоянно маневрировать в физической и цифровой средах. Наряду с этим гибридным урбанистическим опытом город является объектом репрезентации в компьютерных играх, и мы полагаем, что можно говорить об особой разновидности в реконфигурации городских коммуникаций, когда пользователь-горожанин вовлечен в геймплей-существование виртуального города и при этом он, как физический актор, наблюдает и действует в городе реальном. Наглядным примером эффектов соединения двух городских пространств стала практика реконструкции праздничного парада ко Дню Победы 2020.

\section{Городские праздничные парады в играх и стримах 2020}

9 мая 2020 г., в связи с переносом парада, проводимого в российских городах, многие игроки в онлайн-играх сделали собственные парады, а стримеры, помимо непосредственного участия, освещали происходящее на своих каналах. Отметим, что благодаря стриминговым платформам, буквально в течение нескольких недавних лет, открылось новое место для встречи игроков. Стримы объединяют группу в момент трансляции игры стримером. Став своеобразным онлайновым «третьим местом», стримы наряду с играми меняют восприятие физического пространства, трансформируя его в потенциальную многопользовательскую среду.

Естественно, что в первую очередь проведением парадов заинтересовались сообщества вокруг игр, связанных с боевыми действиями - «World of Tanks», «World of Warships», «Grand Theft Auto V Online», «War Thunder», «Crossout» и др. Стример Михаил Припутень / «Mebius_IW» так обосновал решения об онлайн-парадах: «В связи с текущим положением, в котором мы все находимся, в связи с текущей пандемией... из-за того, что 
парад официальный был отменен, мы решили таким образом поддержать официальный парад, в первую очередь, и почтить память тех, кто приближал этот День Победы. Благодаря этим людям мы и можем этот стрим проводить» (Официальный канал World of Warships, «[RU] Стрим в честь Дня Победы!») [YouTube-канал World of Warships... web].

Игровое пространство, его архитектура и комплекс артефактов имели первостепенное значение для проведения парадов. Все участники так или иначе стремились в чем-то соответствовать настоящему мероприятию: задействовали технику и боевые подразделения (юниты), которые могли бы участвовать в Великой Отечественной войне, выбирали локации, похожие на пространство площадей, старались идти, ехать или лететь в строю. Свои парады создавали и игроки, и официальные команды разработчиков игр. Анализируя онлайн-парады, мы выделяем три основных способа симуляции и расширения городского опыта в прошедших игровых парадах 2020:

- полная реконструкция;

- частичная реконструкция;

- творческая интерпретация.

Рассмотрим подробнее каждый из способов.

При полной реконструкиия городского опыта были реализованы попытки с максимальной точностью показать настоящий парад и настоящие локации. Команда разработчиков игры «World of Warships» сделали парад сами, без участия игроков. Для парада, по словам создателей, была воссоздана в мельчайших подробностях акватория Невы. Парадным строем прошли корабли Балтийского, Черноморского, Северного и Тихоокеанского флотов, а также корабли союзников. Аналогично парадам, обычно проходящим в Петербурге, зрители видели и исторические корабли, принимавшие участие в Великой Отечественной войне, и новейшие разработки. Для каждого корабля-участника были представлены тактико-технические характеристики, история создания и героический путь в военных действиях. Для полного аудиального погружения в атмосферу парада использовались песни военных лет, а для комментирования парада был приглашен Евгений Хорошевцев - ведущий (диктор) парадов Победы на Красной площади. Для демонстрации события камера меняла перспективу наблюдения, летала над действом, то удаляясь, то приближаясь вплотную, создавая эффект присутствия в разных точках. Максимально идентичное воспроизведение ландшафта и высокая точность графики заставляли зрителя забыть, что он смотрит виртуальный парад моделей кораблей, и создавала ощущение живого присутствия в Невской акватории.

Создатели игры «War Thunder» воссоздали торжественный военный парад стран-союзников в честь победы во Второй мировой войне, проходивший 7 сентября 1945 г. на территории освобожденного Берлина у Бранденбургских ворот. Для реконструкции парада использовался фрагмент игровой карты «Берлин». В парадном строю прошли колонны военнослужащих и военной техники СССР, Великобритании и США. Были точно воссозданы послевоенный ландшафт, сами Бранденбургские ворота, особенности вооружения и обмундирования солдат разных армий и участвовавшая боевая техника. Торжественный голос комментатора сообщал о боевых заслугах проходящих воинских подразделений, мобильной техники и авиации [YouTube-канал War Thunder... web].

Разработчики игры «Multi Theft Auto. Province» для парада выбрали воссозданную в подробностях Дворцовую площадь Санкт-Петербурга (в игре - город Невский). Эта локация не создавалась специально для парада, она является одной из действующих локаций игры. Участниками парада стали реально существующие игроки и присутствовавшая в игре боевая автотехника. Воссоздана процедура парада: выезжали кабриолеты с главнокомандующим и командующим парадом, проходила механизированная колонна, в составе которой «более 45 единиц современной боевой техники, стоящей на вооружении провинциальной армии» (Максим Ковалев, «Парад Победы на Дворцовой площади Провинции») [YouTube-канал Максим Ковалев... web]. Парад был озвучен в стилистике парадов на Красной площади: оглашались полагающиеся военные приветствия, о каждой единице боевой техники давалась справка о характеристиках и участии в Великой Отечественной войне.

Частичная реконструкиия военного nарада предполагала использование возмож- 
ностей игры (локаций, техники, персонажей, оружия) для повторения парада или соответствия эпохе Великой Отечественной войны. Например, стример КоПанда во время стрима по игре «Roblox Tower Battles» говорит следующее: «Я устраиваю в Роблоксе импровизированный День Победы, чтобы отдать дань уважения нашим дедам... И давайте же как всегда соберем колоду, которая у нас будет состоять, ребята, из юнитов, которые по возможности, у нас участвовали во Второй мировой войне. Мы уберем всех миниганщиков и оставим чисто тех ребят, которые понастоящему могли воевать, в те далекие, непростые времена... Для нашего парада мы конечно же возьмем Командира, который будет командовать нашей армией. Также, ребята, АКа. Он, конечно, наемник, но выглядит он с обычным русским автоматом Калашникова... С ней [с такой колодой], конечно же, будет «затащить» очень тяжело. Но моя цель устроить здесь импровизированный парад Победы, посвященный 9 мая» (КоПанда, «ПАРАД ПОБЕДЫ на 9 МАЯ в РОБЛОКС ТОВЕР БАТЛС») [YouTube-канал КоПанда... web]. В этом примере игрок-стример не воссоздает точного городского пространства и участников военных действий, он использует специфические игровые возможности Роблокса для создания среды, хотя бы как-то напоминающей историческую войну середины XX в.: выбирает соответствующие эпохе боевые юниты (солдат, а они в игре похожи на мини-фигурки Lego) и карту с площадкой. Он реконструирует и врагов: «Так, у нас идет Некромансер, ребята! Это фриц. Фрица надо убивать, тем более, он идет по нашей Красной площади» (КоПанда, «ПАРАД ПОБЕДЫ на 9 МАЯ в РОБЛОКС ТОВЕР БАТЛС») [YouTube-канал КоПанда... web]. Локация «Красная площадь» воссоздается весьма условно, это просто центральное пространство в игровой зоне «Roblox Tower Battles». Однако стример обращается традиционному месту проведения парадов, чтобы воспроизвести дух и ощущение реального праздника.

Парад Победы в игре «GREENTECH $\mathrm{RP} \mid \mathrm{GTA}$ CRMP» проводился самими игроками в пространстве центральной площади Кремля игрового города Нижегородска и комментировался в нескольких стримах (например, стример It's Samarin, «ПАРАД ПОБЕДЫ HAGREENTECH RP| GTA CRMP) [YouTubeканал It's Samarin... web]. Участниками стали игроки, собравшиеся в одно время в одном месте внутри игрового пространства. Закадровый голос произнес короткую торжественную речь. Была сделана традиционная минута молчания. Под песню «День Победы» пехотные отряды с флагами, боевая техника и игровая авиация прошли/пролетели через площадь и главную улицу. Парад проходил онлайн, в прямом эфиpe, стройность прохождения парадного строя зависела от вклада каждого игрока.

В отличие от игры «GREENTECH $\mathrm{RP} \mid \mathrm{GTA} C \mathrm{CR} M$ », где действие разворачивалось в вымышленном городе, парад в игре «WORLD OF TANKS» проходил в подробно смоделированном Минске, то есть на одной из игровых карт «Минск». Зрители видели центр города, от цирка до площади Победы 70x годов XX века. Когда была разработана эта карта, на официальном сайте игры ей была дана следующая характеристика: «Мы постарались как можно точнее изобразить здания, улицы и парки. Для этого использовали множество архивных фото и городских планов. И хотя местность пришлось немного подкорректировать для удобства игрового процесса, результат все равно очень напоминает реальный Минск. Учитывая, что город в этом районе не слишком изменился за последние десятилетия, вы буквально окажетесь на виртуальной экскурсии» [Карта «Минск» ... web]. При проведении парада 9 мая 2020 г. на игровой карте «Минск» можно было наблюдать движение боевых расчетов пяти танков, которыми управляли игроки в реальном времени, аудиальное сопровождение ограничивалось песнями военных лет, комментирования не бЫЛо (STEEL CLAN, «ПАРАД ПОБЕДЫ!!! В WORLD OF TANKS 9 МАЯ 2020») [YouTube-канал STEEL CLAN... web].

Творческой интерпретацией городских торжеств мы называем игровые парады, посвященные 9-му Мая, проходившие без реконструкции аудио- и видео характеристик исторических событий и в ландшафтах вымышленных городов. В этих случаях организаторами празднования использовались игровые локации, основной характеристикой которых была возможность вместить всех желающих. 
Парадным строем проходило все, что ходит, ездит, летает в игре.

Праздничный парад в игре «CROSSOUT» базировался на торжественном проезде групп игроков по горной локации. Вот как об этом сообщает стример ENERGO DED: «Открывает парад объединенная фракция Степные волки. Они наиболее организованы и пунктуальны. Они единственные, кто прибыл первыми в точку сбора в полном составе... Технического вооружения они не раскрывают, видно только, что у них на борту автопушки «Смерч». Приветствуем Степных волков, и в честь Дня Победы они открывают огонь. Ура, товарищи!... В начале колонны наша боевая подруга «Кисуня-красуня» на грузовике былых войн... Далее игрок «Рго» который приехал на тракторе» (ENERGO DED, «ПАРАД ПОБЕДЫ в КРОССАУТ») [YouTube-канал ENERGO DED... web].

Майский парад был проведен и в игре «GTA ONLINE», включавший проход колонн боевой техники, доступной в игре, через город Лос-Сантос (вдохновленный Лос-Анджелесом). Центр виртуального города Лос-Сантоса застроен высокими небоскребами, но за пределами центра игроки могут попасть и в гетто или в рыночный район Маркет. Там есть разнообразная городская инфраструктура: два пляжа, Санта-Мария и Верона, аэропорт и морской порт, и в этой кибер-Калифорнии по улицам и проспектам, где растут пальмы, ехали автомобили и танки, летели самолеты. Интересен опыт стримера Чарли Фрая, участвовавшего в параде и комментировавшего происходившее: «Вот представьте, насколько сложно, тем, кто в реальном параде над Красной площадью пролетают над Москвой. Насколько там точные должны быть действия, потому что они летят плотной колонной и при этом они летят в городской застройке. Это сложно и реально большая ответственность. Мы же куда-то летим сейчас... я не знаю» (Чарли Фрай, «ПАРАД ПОБЕДЫ В GTA ONLINE!») [YouTube-канал Игровой канал... web].

Резюмируем: 9 мая 2020-го года разнообразные городские ландшафты внутри игровых пространств вместили праздничные парады, которые благодаря трансляции в стримах, стали более широкими публичными акциями, доступными не только игрокам, но любым зашедшим на YouTube. Анализируя доступный пользователям опыт, мы видим возможные его варианты, которые располагаются на пересечении двух осей: 1) «наблюдатель парада - участник парада», 2) «место действия совпадает с местом нахождения пользователя - место действия не совпадает с местом нахождения пользователя». Следовательно, можно было получить не только интенсивный опыт городского парада (если вы зритель или участник действия в подлинных декорациях), но также совершить своеобразный хакинг виртуального города (если туда внесены аудио- и видеодетали российского / советского событийного ряда).

\section{Заключение}

Эксперименты в области дизайна внутреннего пространства компьютерных игр преодолели ранние технологические ограничения, и сегодня разработчики применяют инструменты проектирования, фотореалистичного моделирования, программирования и симуляции с прототипами сред, начиная от погодноклиматических условий и заканчивая управлением дорожным движением, от процедурно генерируемого поведения толпы до свойств материалов зданий и физики света. Эти прототипы могут быть сконфигурированы для создания самых разнообразных интерфейсов, изображающих виртуальные города в разных масштабах и с разными целями, часто легко интегрируя микромасштабы, сфокусированные на воссоздании взаимодействий на улице, до макромасштабов, которые фокусируются на демонстрации полной динамики в общем масштабе города.

Когда происходит переход от статичных интерфейсов к мобильным, пользователям больше не нужно сидеть перед своими компьютерами, они перемещаются по городским пространствам, которые уже являются средами социальных коммуникаций. Традиционные общественные места, такие как транспорт, площади, кафе и др. реконфигурируются в гибридные пространства, поскольку горожане двигаются внутри материальных сред, будучи подключенными в реальном времени к другим, виртуальным средам. Социологи неоднократно рассматривали меняющийся опыт 
городских коммуникаций при вовлечении горожан в игры на основе геолокации. Вместе с тем переживание событий в городе преобразуется и при обращении к другим компьютерным играм. Например, если какой-либо процесс, характерный для реальной городской жизни, мультиплицируется в виртуальных городах. Так произошло с парадом ко Дню Победы в 2020-м г., который 9 Мая не мог пройти офлайн, но был проведен внутри игровых городов. Актуализировались возможности виртуальных игр давать место для общения и поддержания культурных образцов, в частности - для проведения городских ритуалов. Такое культурное погружение в ритуализированные практики позволяет тем, кто в них участвует, сохранить ощущение порядка, сделать мир снова понятным и безопасным.

\section{ПРИМЕЧАНИЕ}

1 Людография: 1) SimCity (1989) Maxis; 2) Mogi (2004) Geocaching; 3) Pokemon GO (2016) Niantic Inc., Nintendo, The Pokemon Company; 4) Ingress (2013) Niantic Inc; 5) Johnny the Skull (2016) Fotorama; 6) World of Tanks (2010) Wargaming.net; 7) World of Warships (2015) Wargaming.net, Lesta Studio; 8) Grand Theft Auto V Online (2013) Rockstar North; 9) War Thunder (2013) Gaijin Entertainment; 10) Crossout (2017) Targem games; 11) Multi Theft Auto. Province (2006) MTA Team; 12) Roblox Tower Battles (2011) Planet3arth; 13) GREENTECHRP|GTA CRMP(2014) GreenTech RolePlay, CRime team, Rockstar North.

\section{СПИСОК ЛИТЕРАТУРЫ}

Вахштайн web - Вахштайн В.C. Трансформация общественных пространств и эволюция социальной коммуникации (The Transformation of Public Space and the Evolution of Social Communication) (May 30, 2016) // https:// papers.ssrn.com/sol3/papers.cfm?abstract id $=2833366$.

Ветушинский 2017 - Ветушинский А.С. Исследование игровых пространств: встреча гейм-дизайна и архитектуры. Рецензия на книгу: Space. Time. Play. Computer Games, Architecture and Urbanism: The Next Level (2007) F. von Borries, S.P. Walz, M. Böttger (eds), Basel; Boston; Berlin: Birkhäuser // Социология власти. 2017. Т. 29 (1). С. 258-275.

Глазков 2015 - Глазков К.П. Игровое столкновение в эпоху его цифровой воспроизводи- мости // Социология власти. 2015. Т. 27 (№ 4). С.72-92.

Глазков 2017 - Глазков К.П. Телесное присутствие в геолокационных играх // Социология власти. 2017. Т. 29(3). С. 163-196.

Горбушина, Чеботарев 2020 - Горбушина М.A., Чеботарев A.M. Истоки компьютерной графики в видеоиграх // IX Лазаревские чтения «Лики традиционной культуры в современном культурном пространстве: память культуры и культура памяти»: сб. материалов Междунар. науч. конф. (г. Челябинск, 26 февр. - 2 марта). Челябинск: ЧГИК, 2020. С. 108-109.

Ильин 2020 - Ильин К.С. Дизайн и архитектура в видеоиграх // Новые идеи для нового века. 2020. №3. С. 173-180.

Карта «Минск»... web - Карта «Минск». Игра и реальность // https:/worldoftanks.ru/ru/news/ common/karta-minsk-igra-i-realnost.

Королева и др. 2017 - Королева Д.О., Кочервей А.И., Насонова (Арно) К.М., Шибеко Ю.В. Игра «Покемон Го» как кросс-культурный феномен // Игровая культура современного детства: материалы I Междунар. науч.-практ. конф. (г. Москва, 28-30 сентября 2016 г.). В 2 т. Т. 1. М.: НАИР, 2017. С. 31-40.

МакГонигл 2015 - МакГонигл Д. Настоящая маленькая игра: эффект Пиноккио в первазивных играх // Философско-литературный журнал «Логос». 2015. Т. 25, № 1 (103). С. 130-156.

Маккуайр 2014 - Маккуайр С. Медийный город. Медиа, архитектура и городское пространство. М.: Strelka Press, 2014.

Саблина 2018 - Саблина А.A. Следуя за ловцами покемонов: городское пространство, комьюнити и российский контекст // Молодежь Европы и России. Европа и Европейский союз глазами ученых: материалы Междунар. науч. конф. (г. Томск, 17-19 мая 2018 г.). Томск: Издво Томск. ун-та, 2018. С. 59-63.

Салин, Галанина 2016-Салин А.С., Галанина E.B. Миссия выполнена: насколько свободен геймер в виртуальном мире видеоигры? // Контекст и рефлексия: философия о мире и человеке. 2016. Т. 5 (№ 5A). С. 160-177.

Álvarez, Duarte 2018 -Álvarez R., Duarte F. Spatial Design and Placemaking: Learning from video games // Space and Culture. 2018. Vol. 21 (3). P. 208-232.

Borries, Walz, Böttger (eds.) 2007 - Borries von F., Walz S.P., Böttger M. (eds.). Space. Time. Play. Computer Games, Architecture and Urbanism: The Next Level. Basel; Boston; Berlin: Birkhäuser, 2007.

De Souza, Frith 2012 - De Souza A.S., Frith J. Mobile Interfaces in Public Spaces: Locational Privacy, 
Control, and Urban Sociability. N. Y.: Routledge, 2012.

De Souza, Hjorth 2009 - De Souza A.S., Hjorth L. Urban Spaces as Playful Spaces: A Historical Approach to Mobile Urban Games // Simulation and Gaming. 2009. Vol. 40 (5). P. 602-625.

Koutsabasis 2012 - Koutsabasis P. On the Value of Virtual Worlds for Collaborative Design // Design Studies. 2012. Vol. 33. P. 357-390.

Leorke 2018 - Leorke D. Location-Based Gaming: Play in Public Space. Gateway East: Palgrave Macmillan, 2018.

Licoppe 2017 - Licoppe C. From Mogi to Pokemon Go. Continuities and change in location aware collection games // Mobile Media and Communication. 2017. Vol. 5 (1). P. 24-29.

Minnery, Searle 2014 - Minnery J., Searle G. Toying with the City? Using the Computer Game SimCity ${ }^{\mathrm{TM}} 4$ in Planning Education // Planning Practice \& Research. 2014. Vol. 29. P. 41-55.

Nitsche 2008 - Nitsche M. Video Game Spaces. Image, Play, and Structure in 3D Game Worlds. Cambridge; L.: The MIT Press, 2008.

Sicart 2017 - Sicart M. Reality has always been augmented: Play and the promises of Pokémon GO // Mobile Media \& Communication. 2017. Vol. 5(1). P. 30-33.

Walz 2010 - Walz S.P. Toward a Ludic Architecture. The Space of Play and Games. Pittsburgh: ETC Press, 2010.

\section{ИСТОЧНИКИ}

YouTube-канал Игровой канал Чарли Фрая. ПАРАД ПОБЕДЫ В GTA ONLINE! // https:// www.youtube.com/watch? $\mathrm{v}=\mathrm{m} 686 \mathrm{xD} 0 \mathrm{zh} \mathrm{VM}$ (дата обращения: 10.12.2020).

YouTube-канал КоПанда. ПАРАД ПОБЕДЫ на 9 МАЯ в РОБЛОКС ТОВЕР БАТЛС Tower Battles Roblox // https://www.youtube.com/watch?v= 9nn2CTYnhIc (дата обращения: 10.12.2020).

YouTube-канал Максим Ковалев. «Парад Победы на Дворцовой площади Провинции» // https:// www.youtube.com/watch?v=jsBN51GS7P8 (дата обращения: 10.12.2020).

YouTube-канал ENERGO DED. ПАРАД ПОБЕДЫ в КРОССАУТ [Игра CROSSOUT] // https:// www.youtube.com/watch? $\mathrm{v}=-\mathrm{b} 3$ PCau59U0 (дата обращения: 10.12.2020).

YouTube-канал It's Samarin. ПАРАД ПОБЕДЫ 2020 HA GREENTECH RP | GTA CRMP // https:// www.youtube.com/watch? $v=$ V9LggrXpOIs (дата обращения: 10.12.2020).

YouTube-канал STEEL CLAN. ПАРАДПОБЕДЫ!!! В WORLD OF TANKS 9 МAЯ $2020 / / \mathrm{https} / /$
www.youtube.com/watch?v=Fi2rUiAhXc0 (дата обращения: 10.12.2020).

YouTube-канал War Thunder. Официальный канал. ПАРАД ПОБЕДЫ / War Thunder // https:// www.youtube.com/watch?v=wQW5bDsQgPE (дата обращения: 10.12.2020).

YouTube-канал World of Warships [WoWS]. Официальный канал. «[RU] Стрим в честь Дня Победы!»// https://www.youtube.com/ watch?v=y_zMaUd4c3A (дата обращения: 10.12.2020).

\section{REFERENCES}

Vahshtajn V.S., 2016. The Transformation of Public Space and the Evolution of Social Communication. URL: https://ssrn.com/ abstract=2833366 or http://dx.doi.org/10.2139/ ssrn.2833366 (accessed 9 December 2020).

Vetushinskij A.S., 2017. Exploration of Game Spaces: A Meeting Between Game Design and Architecture. Sotsiologiya vlasti, vol. 29(1), pp. 258-275.

Glazkov K.P., 2017. Physical Presence in Geolocation Games. Sotsiologiya vlasti, vol. 29 (3), pp. 163-196.

Glazkov K.P., 2015. Gaming Clash in the Age ofDigital Reproducibility. Sotsiologiya vlasti, vol. 27 (4), pp. 72-92.

Gorbushina M.A., Chebotarev A., 2020. The Origins of Computer Graphics in Video Games. IX Lazarevskie chteniya "Liki traditsionnoy kultury v sovremennom kulturnom prostranstve: pamyat kultury i kultura pamyati»: $s b$. materialov mezhdunar. nauch. konf. Chelyabinsk, CHGIK Publ., pp. 108-109.

Ilyin K.S., 2020. Design and Architecture in Video Games. Novye idei dlya novogo veka, no. 3, pp. 173-180.

Map "Minsk"... web - Map "Minsk". Game and Reality. URL: https:/worldoftanks.ru/ru/news/ common/karta-minsk-igra-i-realnost.

Koroleva D.O., Kochervej A.I., Nasonova (Arno) K.M., Shibeko Yu.V., 2017. Game «Pokemon Go» as a Cross-Cultural Phenomenon. Igrovaya kultura sovremennogo detstva: materialy I Mezhdunar. nauch.-prakt. konf. Vol. 1. Moscow, NAIR Publ., pp. 31-40.

MakGonigl D., 2015. Real LittleGame: The PinocchioEffect in Pervasive Games. Filosofsko-literaturnyy zhurnal «Logos», vol. 25, no. 1 (103), pp. 130-156.

Makkuajr S., 2014. Media City. Media, Architecture and Urban Space. Moscow, Strelka Press.

Sablina A.A., 2018. Following the Pokemon Catchers: Urban Space, Community and the Russian Context. Molodezh Evropy i Rossii. Evropa $i$ Evropejskiy soyuz glazami uchenykh: materialy mezhdunar. nauch. konf. Tomsk, Izd-vo Tomskogo universiteta, pp. 59-63. 
Salin A.S., Galanina E.V., 2016. Mission Accomplished: How Free is a Gamer in the Virtual World of a Video Game? Kontekst i refleksiya: filosofiya o mire i cheloveke, vol. 5, no. 5A, pp. 160-177.

Álvarez R., Duarte F., 2018. Spatial Design and Place making: Learning from Video Games. Space and Culture, vol. 21 (3), pp. 208-232.

Borries von F., Walz S.P., Böttger M. (eds.), 2007. Space. Time. Play. Computer Games, Architecture and Urbanism: The Next Level. Basel; Boston; Berlin, Birkhäuser.

De Souza A.S., Frith J., 2012. Mobile Interfaces in Public Spaces: Locational Privacy, Control, and Urban Sociability. N.Y.: Routledge.

De Souza A.S., Hjorth L., 2009. Urban Spaces as Playful Spaces: A Historical Approach to Mobile Urban Games. Simulation and Gaming, vol. 40 (5), pp. 602-625.

Koutsabasis P., 2012. On the Value of Virtual Worlds for Collaborative Design. Design Studies, vol. 33, pp. 357-390.

Leorke D., 2018. Location-Based Gaming: Play in Public Space. Gateway East, Palgrave Macmillan.

Licoppe C., 2017. From Mogi to Pokemon Go. Continuities and Change in Location Aware Collection Games. Mobile Media and Communication, vol. 5 (1), pp. 24-29.

Minnery J., Searle G., 2014. Toying with the City? Using the Computer Game SimCity ${ }^{\mathrm{TM}} 4$ in Planning Education. Planning Practice \& Research, vol. 29, pp. 41-55.

Nitsche M., 2008. Video Game Spaces. Image, Play, and Structure in 3D Game Worlds. Cambridge; London, The MIT Press.

Sicart M., 2017. Reality Has Always Been Augmented: Play and the Promises of Pokémon GO. Mobile Media \& Communication, vol. 5 (1), pp. 30-33.

Walz S.P., 2010. Toward a Ludic Architecture. The Space of Play and Games. Pittsburgh, ETC Press.

\section{SOURCES}

YouTube-kanal Igrovoy kanal Charli Fraya. PARAD POBEDY V GTA ONLINE! [YouTube Channel Charlie Fry's Game Channel. VICTORY PARADE IN GTA ONLINE!]. URL: https://
www.youtube.com/watch?v=m686xD0zhVM (accessed 10 December 2020).

YouTube-kanal KoPanda. PARAD POBEDY na 9 MAYa v ROBLOKS TOVER BATLS Tower Battles Roblox [YouTube Channel KoPanda. VICTORY PARADE on MAY 9 in ROBLOKS TOVER BATTLES Tower Battles Roblox]. URL: https:// www. youtube. com/watch? $\mathrm{v}=9 \mathrm{nn} 2 \mathrm{CTYnhIc}$ (accessed 10 December 2020).

YouTube-kanal Maksim Kovalev. «Parad Pobedy na Dvortsovoy ploshchadi Provintsii» [Maxim Kovalev's YouTube Channel. "Victory Parade on the Palace Square of the Province"]. URL: https:// www.youtube.com/watch? $v=$ jsBN51GS7P8 (accessed 10 December 2020).

YouTube-kanal ENERGO DED. PARAD POBEDY v KROSSAUT [Igra CROSSOUT] [YouTube Channel ENERGODED. VICTORY PARADE in CROSSOUT [Crossout Game]]. URL: https:// www.youtube.com/watch?v=-b3PCau59U0 (accessed 10 December 2020).

YouTube-kanal It's Samarin. PARAD POBEDY 2020 NA GREENTECH RP | GTA CRMP [YouTube Channel It's Samarin. VICTORY PARADE 2020 at GREENTECH RP|GTA CRMP]. URL: https:// www.youtube.com/watch? $\mathrm{v}=\mathrm{V} 9 \mathrm{LggrXpOIs}$ (accessed 10 December 2020).

YouTube-kanal STEEL CLAN. PARADPOBEDY!!! V WORLD OF TANKS 9 MAYa 2020 [YouTubeChannel STEEL CLAN. PREDPOVEDI!!! In WORLD OF TANKS MAY 9, 2020]. URL: https:/ /www.youtube.com/watch? $\mathrm{v}=\mathrm{Fi} 2 \mathrm{rUiAhXc0}$ (accessed 10 December 2020).

YouTube-kanal War Thunder. Ofitsialnyy kanal. PARAD POBEDY / War Thunder [War Thunder YouTube Channel. Official Channel. VICTORY PARADE / War Thunder]. URL: https:// www.youtube.com/watch?v=wQW5bDsQgPE (accessed 10 December 2020).

YouTube-kanal World of Warships [WoWS]. Ofitsialnyy kanal. "[RU] Strim v chest Dnya Pobedy!» [YouTube Channel World of Warships [WoWS]. Official Channel. "[RU] Stream in Honor of Victory Day!']. URL: https:/ /www.youtube.com/watch?v=y_zMaUd4c3A (accessed 10 December 2020). 


\section{Information About the Authors}

Olga V. Sergeyeva, Doctor of Sciences (Sociology), Associate Professor, Leading Researcher, Sociological Institute of the RAS - Branch of the Federal Center of Teoretical and Applied Sociology of the Russian Academy of Sciences, 7-ya Krasnoarmeyskaya St, 25/14, 190005 Saint Petersburg, Russian Federation, o.v.sergeeva@spbu.ru, https://orcid.org/0000-0002-8093-609X

Nadezhda A. Zinovyeva, Candidate of Sciences (Sociology), Associate Researcher, Sociological Institute of the RAS - Branch of the Federal Center of Teoretical and Applied Sociology of the Russian Academy of Sciences, 7-ya Krasnoarmeyskaya St, 25/14, 190005 Saint Petersburg, Russian Federation,n.zinoveva@socinst.ru, https://orcid.org/0000-0002-7809-3409

\section{Информация об авторах}

Ольга Вячеславовна Сергеева, доктор социологических наук, доцент, ведущий научный сотрудник, Социологический институт РАН - филиал ФНИСЦ РАН, ул. 7-я Красноармейская, 25/14, 190005 г. Санкт-Петербург, Российская Федерация, o.v.sergeeva@spbu.ru, https://orcid.org/0000-0002-8093-609X

Надежда Андреевна Зиновьева, кандидат социологических наук, ассоциированный научный сотрудник, Социологический институт РАН - филиал ФНИСЦ РАН, ул. 7-я Красноармейская, 25/14, 190005 г. Санкт-Петербург, Российская Федерация, n.zinoveva@socinst.ru, https://orcid.org/0000-0002-7809-3409 